УДК 621.397.335.1

${ }^{[0000-0002-2046-481 \mathrm{X}]}$ E. В. Фауре, д.m.н., професор,

e-mail: e.faure@chdtu.edu.ua

${ }^{[0000-0001-9360-5460]}$ В. В. Швидкий, к. т.н., дочент,

${ }^{[0000-0002-3049-3497]}$ А. І. Щерба, к.ф.-м.н., дочент,

${ }^{[0000-0003-1791-6755]}$ О. О. Харін, д.філос.,

${ }^{[0000-0002-3185-8427]}$ Б. А. Ступка

Черкаський державний технологічний університет

б-р Шевченка, 460, м. Черкаси, 18006, Україна

\title{
МЕТОД ЦИКЛОВОЇ СИНХРОНІЗАЦІЇ НА ОСНОВІ ПЕРЕСТАНОВОК
}

У роботі розроблено та досліджено метод ииклової синхронізації приймальної та передавальної станцій телекомунікаційних систем передавання інформації з нероздільним факторіальним кодуванням в умовах впливу в каналі зв'язку завад високої інтенсивності. Розроблений метод базується на використанні як синхрокомбінації перестановки чисел, її поділу на префіксну та суфіксну частини, а також на мажоритарній обробиі прийнятих фрагментів. Теоретично визначено та досліджено ймовірнісні показники розробленого методу: ймовірність правильного встановлення синхронізму та ймовірність хибного встановлення синхронізму. Розроблено структурну схему пристрою циклової синхронізаиії. Побудовано програмну модель передавання даних, в якій реалізовано розроблений алгоритм встановлення циклового синхронізму. Оиінено експериментально отримані ймовірнісні характеристики розробленого методу. Підтверджено їх відповідність теоретичним показникам.

Ключові слова: факторіальне кодування, синхрокомбіначія, імовірність встановлення синхронізму, коефічієнт накопичення, завада високої інтенсивності.

Вступ. Процедура циклової синхронізації є невід'ємною частиною всіх стандартних протоколів мережевої взаємодії [1-3]. Під час встановлення з'єднання до процедури перенесення призначених для користувача даних вона реалізує пошук меж синхрокомбінації (роздільника).

У цій роботі розглядаються телекомунікаційні системи 3 нероздільним факторіальним кодуванням. У роботах [4-8] висвітлено базові принципи побудови нероздільних факторіальних кодів та їх характеристики, проте не приділено уваги питанню встановлення циклового синхронізму. Таким чином, на сьогоднішній момент відсутні методи циклової синхронізації для подібних систем передавання даних.

Серед робіт, присвячених процедурам циклової синхронізації, можна виділити роботи [9-13]. Для підвищення ефективності встановлення циклового синхронізму вони, зокрема, передбачають використання підсумовування за модулем два синхрокомбінації з потоком інформаційних даних. Це дає можливість скоротити обсяг службової інформації, переданої каналом зв'язку, для циклової синхронізації повідомлень і більш ефективно ви- користовувати ресурси каналу зв'язку. Разом 3 тим, телекомунікаційні системи з блоковим, зокрема факторіальним, кодом [14], на відміну від систем передавання даних 3 потоковим, наприклад згортковим, кодом [15-16], не дають змоги використовувати такий підхід, оскільки накладення на інформаційний блок синхрокомбінації призводить до катастрофічних деформацій блоку даних і безповоротної втрати інформації. Це виключає можливість застосування зазначеного підходу циклової синхронізації в системах 3 факторіальним кодуванням.

Метою дослідження $\epsilon$ забезпечення входження в цикловий синхронізм телекомунікаційних систем передавання інформації 3 нероздільним факторіальним кодуванням в умовах впливу в каналі зв'язку завад високої інтенсивності.

Для досягнення поставленої мети необхідно вирішити наступні задачі:

- розробити метод і алгоритм встановлення циклового синхронізму для телекомунікаційних систем передавання інформації з нероздільним факторіальним кодуванням; 
- визначити ймовірність встановлення циклового синхронізму для завад різної інтенсивності;

- побудувати модель, яка реалізує розроблений алгоритм встановлення циклового синхронізму;

- виконати порівняння ймовірнісних показників входження в синхронізм для завад різної інтенсивності.

Виклад основного матеріалу. Основною ідеєю для запропонованого в цій роботі методу встановлення циклової синхронізації $\epsilon$ наступне:

- синхрокомбінацією є перестановка $\pi$;

- конструкція синхрокомбінації поділяється на префіксну частину, що визначає межі ії символів, і суфіксну частину, що визначає межі синхрокомбінаціїперестановки;

- підвищення достовірності передавання синхрокомбінації забезпечується іiі багаторазовим повторенням і мажоритарною обробкою прийнятих фрагментів.

Опис методу встановлення циклової синхронізації на основі перестановок

Метод встановлення циклової синхронізації передбачає такі кроки:

1) синхрокомбінацією $\epsilon$ перестановка $\pi$ довжини $M$ символів. Символи перестановки $\pi$ кодуються рівномірним двійковим кодом таким чином, щоб перший символ записувався послідовністю, що складається тільки 3 нулів, а другий тільки $з$ одиниць. Крім того, третій символ синхрокомбінації в двійковому записі повинен починатися нулем, а останній символ повинен закінчуватися двійковою одиницею. Решта символів повинна містити максимальну кількість переходів 3 одиниці в нуль і навпаки (для мінімізації витрат часу на синхронізацію біт) і не повинна містити комбінації 10...01...10;

$$
l_{r} \quad l_{r}
$$

2) під час старту процедури пошуку синхронізму в накопичувач приймача записуються три послідовні фрагменти отриманої 3 каналу послідовності біт. Довжина кожного 3 фрагментів дорівнюе довжині синхрокомбінації $n=M \cdot l_{r}=M\left\lceil\log _{2} M\right\rceil ;$

3) за прийнятими фрагментами формується уточнена послідовність $R$. Кожний біт цієї послідовності обчислюється за мажоритарним принципом на основі відповідних біт прийнятих фрагментів. Таким чином, якщо $i$-ті біти фрагментів містять більше «одиниць», $i$-тому біту уточненої послідовності присвоюється значення «одиниці», в іншому випадку - «нуля»;

4) в уточненій послідовності $R$ з урахуванням ii циклічного зсуву перевіряється наявність комбінації 10...01...10 . $l_{r} \quad l_{r}$

Якщо ii знайдено, причому вона одна, уточнену послідовність $R$ циклічно зсувають таким чином, щоб вона починалася $з$ префікса $0 . .01 . . .1$;

$$
l_{r} \quad l_{r}
$$

5) уточнена послідовність $R$ порівнюється 3 еталоном $\pi$. Якщо вона збігається 3 еталонною синхрокомбінацією 3 точністю до одного з їі символів, то процедура підстроювання циклової фази припиняється, циклічним зсувом компенсується фазова неузгодженість і формується сигнал «Пошук циклової фази завершений». Цей сигнал відправляється на станцію передавання даних і $€$ командою на перехід до процедури передавання даних користувача;

6) якщо комбінацію $10 \ldots 01 . .10$ в уточне\begin{tabular}{ll}
$l_{r} \quad l_{r}$ \\
\hline
\end{tabular}

ній послідовності $R$ не знайдено, знайдено таких комбінацій дві та більше, а також, якщо суфікс уточненої послідовності $R$ відрізняється від суфікса еталонної синхрокомбінації $\pi$ більше, ніж на один символ, то додатково приймаються ще два фрагменти, тим самим збільшуючи їх кількість до п'яти. Знову повторюються всі операції виявлення синхрокомбінації, починаючи 3 п. 3;

7) кількість накопичених фрагментів може послідовно збільшуватися до деякого, наперед заданого порогу. Після досягнення цього порогу кількість накопичених фрагментів не змінюється. Процес пошуку синхронізму триває, поки або не буде знайдений синхронізм, або не закінчиться ліміт часу на виконання пошуку синхронізму. В останньому випадку процедура пошуку синхронізму завершується, а на вихід системи видається сигнал «Аварія каналу».

(c) Е. В. Фауре, В. В. Швидкий, А. І. Щерба, О. О. Харін, Б. А. Ступка, 2020 DOI: $10.24025 / 2306-4412.4 .2020 .222439$ 
Метод встановлення циклової синхронізації можна реалізувати за допомогою пристрою, наведеного на рисунку 1.

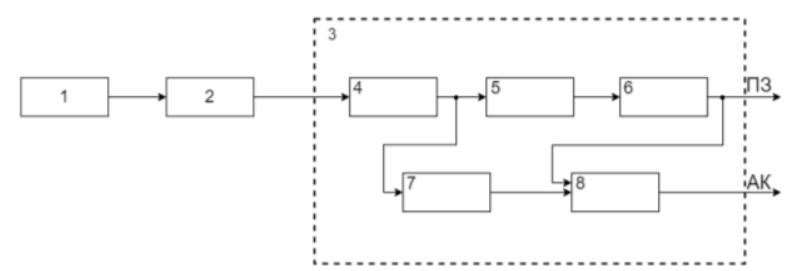

1 - джерело синхрокомбінації; 2 - канал зв'язку;

3 - приймач синхрокомбінації; 4 - накопичувач синхрокомбінації; 5 - пристрій пошуку префікса;

6 - пристрій пошуку суфікса; 7 - лічильник

кількості циклів; 8 - вирішальний пристрій;

П3 - сигнал «пошук синхронізму завершений»; АК - сигнал «Аварія каналу»

Рисунок 1 - Структурна схема пристрою циклової синхронізації

Пояснювати принцип побудови системи циклової синхронізації, що реалізує запропонований метод, будемо на прикладі використання як синхрокомбінації перестановки $\pi$ довжини $\quad M=8$ (послідовності десяткових символів множини $\{0,1,2,3,4,5,6,7\})$.

Кожний символ цієї множини кодується рівномірним двійковим кодом, наприклад, як показано в таблиці 1.

Таблиця 1 - Схема кодування символів перестановки

\begin{tabular}{|l|c|c|c|c|c|c|c|c|}
\hline $\begin{array}{l}\text { Десятковий } \\
\text { запис }\end{array}$ & 0 & 1 & 2 & 3 & 4 & 5 & 6 & 7 \\
\hline $\begin{array}{l}\text { Двійковий } \\
\text { запис }\end{array}$ & 000 & 001 & 010 & 011 & 100 & 101 & 110 & 111 \\
\hline
\end{tabular}

Сконструюємо

синхрокомбінацію 3 префіксом, що виявляе межі символів. Таким префіксом може бути комбінація, складена 3 першого та останнього символів множини $\{0,1,2,3,4,5,6,7\}$ - символів 0 і 7. Останній символ синхрокомбінації повинен закінчуватися одиницею, а перший символ суфікса повинен починатися нулем. Решта символів обираються таким чином, щоб кількість знакозмін (змін двійкової одиниці на двійковий нуль або навпаки - нуля на одиницю) було максимальним.

Діаграму розподілу кількості перестановок з повної множини перестановок довжини $M=8$, символи яких закодовано відповідно до схеми таблиці 1 , залежно від кількості знакозмін зображено на рисунку 2.

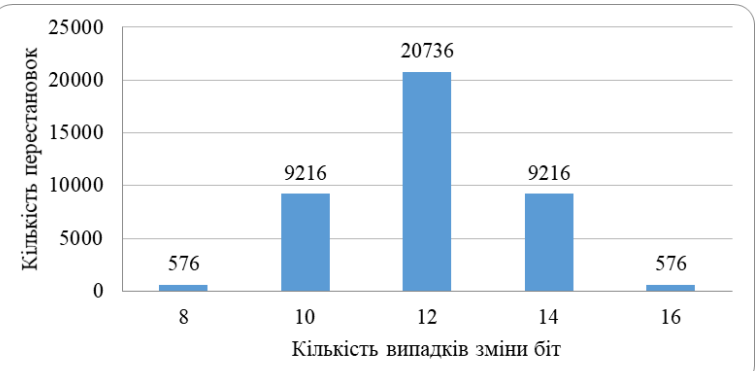

Рисунок 2 - Діаграма розподілу кількості перестановок залежно від кількості знакозмін

3 рисунка 2 видно, що найбільша можлива кількість переходів 30 в 1 та 31 в 0 дорівнює 16. Виконаємо пошук перестановок, де перші символи - 0 і 7, останній символ закінчується двійковою одиницею, перший символ суфікса починається двійковим нулем, а сама перестановка містить 16 знакозмін. Знайдені експериментальним шляхом такі перестановки наведено в таблиці 2.

Таблиця 2 - Перелік перестановок довжини $M=8$ для використання як синхрокомбінації

\begin{tabular}{|c|c|c|}
\hline$№$ & Десятковий запис & Двійковий запис \\
\hline 1 & $(0,7,1,2,4,6,5,3)$ & $(000,111,001,010,100,110,101,011)$ \\
\hline 2 & $(0,7,1,2,6,4,5,3)$ & $(000,111,001,010,110,100,101,011)$ \\
\hline 3 & $(0,7,1,3,2,4,6,5)$ & $(000,111,001,011,010,100,110,101)$ \\
\hline 4 & $(0,7,1,3,2,6,4,5)$ & $(000,111,001,011,010,110,100,101)$ \\
\hline 5 & $(0,7,2,4,6,5,1,3)$ & $(000,111,010,100,110,101,001,011)$ \\
\hline 6 & $(0,7,2,4,6,5,3,1)$ & $(000,111,010,100,110,101,011,001)$ \\
\hline 7 & $(0,7,2,6,4,5,1,3)$ & $(000,111,010,110,100,101,001,011)$ \\
\hline 8 & $(0,7,2,6,4,5,3,1)$ & $(000,111,010,110,100,101,011,001)$ \\
\hline 9 & $(0,7,3,1,2,4,6,5)$ & $(000,111,011,001,010,100,110,101)$ \\
\hline 10 & $(0,7,3,1,2,6,4,5)$ & $(000,111,011,001,010,110,100,101)$ \\
\hline 11 & $(0,7,3,2,4,6,5,1)$ & $(000,111,011,010,100,110,101,001)$ \\
\hline 12 & $(0,7,3,2,6,4,5,1)$ & $(000,111,011,010,110,100,101,001)$ \\
\hline
\end{tabular}

Одна з наведених у таблиці 2 послідовностей записується в постійний запам'ятовувальний пристрій (ПЗП), який стане джерелом синхрокомбінації передавальної станції.

Розглянемо процедури, реалізовані на приймальній станції.

Перш за все, зазначимо, що в приймач надходить синхрокомбінація, уражена дією завади в каналі зв'язку і зсунута за фазою що- 
до положення ковзного вікна (виконаного у вигляді регістра зсуву). Водночас ні інтенсивність завади, ні зсув ковзного вікна (величина фазової неузгодженості циклів передавача та приймача) апріорно невідомі. Тому першим завданням системи циклової синхронізації є підвищення достовірності прийнятих даних, а другим - визначення та компенсація фазової неузгодженості.

Підвищення достовірності прийнятих даних досягається багаторазовим повторенням синхрокомбінації та накопиченням результату. Так, коефіцієнтом накопичення, який дорівнює кількості накопичуваних фрагментів отриманої з каналу послідовності біт, довжина кожного 3 яких дорівнює довжині синхрокомбінації, обирається з ряду непарних чисел $3,5,7 \ldots$ Очевидно, що чим вищий коефіцієнт накопичення, тим більша ймовірність правильного рішення (тобто менша ймовірність помилкової синхронізації) та більший час входження в синхронізм. У запропонованому методі циклової синхронізації виконується адаптивний підбір коефіцієнта накопичення (чим гірший канал зв'язку, тим більшим встановлюється коефіцієнт накопичення). Це досягається тим, що прийнята 3 каналу зв'язку послідовність біт записується в буферний накопичувач (блок 4 рисунка 1) загальною ємністю, наприклад, 11 синхрокомбінацій. Під час старту процедури пошуку синхронізму встановлюється мінімальне значення коефіцієнта накопичення $l=3$, після чого в буферний накопичувач записуються три фрагменти прийнятої послідовності, довжина кожного 3 яких дорівнює довжині синхрокомбінації. Циклічний зсув прийнятої послідовності випадковий. За цими трьома фрагментами мажоритарно обчислюється уточнена послідовність $R$, в якій частину помилок (якщо вони є) виправлено - зазначеною процедурою виправляються всі помилки кратністю до $\frac{l-1}{2}$ включно, які виникають у відповідних бітах прийнятих фрагментів. Відповідно, максимальна загальна кількість бітових помилок, яку здатна виправити мажоритарна обробка, становить $\frac{l-1}{2} n=\frac{l-1}{2} M\left\lceil\log _{2} M\right\rceil$ з прийнятих $\ln$ біт. Наприклад, для $M=8$ i $l=3$ це значення дорівнює 24 бітові помилки 3 прийнятих 72 біт. Для $M=8$ і $l=5$ - збільшується до 48 зі 120 біт.
У накопичувачі 4 виконується побітовий циклічний зсув уточненої послідовності $R$, за яким дешифратор префікса 5 після виконання кожного зі зсувів перевіряє, чи виявлено префікс синхрокомбінаціі. Якщо префікс виявлено, то перевіряється і суфікс (блок 6). Якщо обидві перевірки завершено позитивно, то процедуру адаптації коефіцієнта накопичення до якості каналу зв'язку завершено, а синхронізм встановлено. У цьому випадку дешифратор суфікса 6 видає сигнал «Пошук синхронізму завершений» (П3). Він відправляється зворотним каналом на передавальну станцію, а канал даних переходить зі стану встановлення з'єднання в стан перенесення призначених для користувача даних.

Якщо дешифратором префікса 5 не виявлено префікса синхрокомбінації або дешифратором суфікса 6 не підтверджено цілісність синхрокомбінації, тобто для визначеного значення коефіцієнта накопичення синхрокомбінацію не визначено, то в накопичувач 4 додатково записуються два фрагменти отриманої 3 каналу послідовності біт. Після цього обчислюється уточнена після мажоритарної обробки п'яти фрагментів послідовність, за якою дешифратор префікса 5 і дешифратор суфікса 6 виконують виявлення синхрокомбінації. Якщо і ця спроба виявити префікс і суфікс синхрокомбінації блоками 5 і 6 є невдалою, то коефіцієнт накопичення збільшується ще на два. Збільшення коефіцієнта накопичення триває доти, поки не буде досягнуто його граничне значення, рівне, наприклад, 11. Далі пошук синхронного стану триває або до завершення процедури пошуку, або до вичерпання ліміту часу на пошук синхронізму. Для цього система циклової синхронізації містить лічильник кількості циклів 7, вхід якого підключений до виходу накопичувача 4, а вихід - до першого входу вирішального пристрою 8. Другий вхід вирішального пристрою підключений до виходу дешифратора суфікса 6 , який виводить сигнал ПЗ. Якщо після закінчення ліміту часу, відведеного на пошук синхронізму, він не знайдений, то вирішальний пристрій 8 формує сигнал «Аварія каналу». Процедура пошуку припиняється.

Імовірнісні показники встановлення циклового синхронізму

Теоретично визначимо один 3 основних показників системи циклової синхронізації ймовірність встановлення циклового синхронізму за $l$ прийнятими фрагментами, 
$l=3,5, \ldots$, залежно від імовірності бітової помилки $p_{0}$ у каналі зв'язку.

Імовірність бітової помилки в уточненій послідовності $R$ після мажоритарної обробки $l$ прийнятих фрагментів

$$
p_{0}^{*}=\sum_{i=(l+1) / 2}^{l} C_{l}^{i} p_{0}^{i}\left(1-p_{0}\right)^{l-i} .
$$

Помилка в символі перестановки виникає тоді, коли хоча б один біт у його двійковому представленні в уточненій послідовності $R$ визначено неправильно. Імовірність такої події

$$
\begin{aligned}
& p_{\text {symb }}=\sum_{i=1}^{l_{r}} C_{l_{r}}^{i}\left(p_{0}^{*}\right)^{i}\left(1-p_{0}^{*}\right)^{l_{r}-i}= \\
& =1-\left(1-p_{0}^{*}\right)^{l_{r}} .
\end{aligned}
$$

Система циклової синхронізації прийме правильне рішення про встановлення циклового синхронізму, якщо:

1) перші два символи (двійкове представлення яких містить усі нулі та всі одиниці) уточненої послідовності $R$ буде визначено без помилки;

2) третій символ уточненої послідовності $R$ буде починатися з двійкового нуля;

3) останній символ уточненої послідовності $R$ буде закінчуватися двійковою одиницею;

4) не більше одного 3 групи від третього до останнього символів уточненої послідовності $R$ визначено неправильно. Імовірність першої події

$$
P_{1}=\left(1-p_{\text {symb }}\right)^{2} \text {. }
$$

Імовірність того, що одночасно відбудуться друга, третя та четверта події,

$$
\begin{aligned}
& P_{2-4}=\left(1-p_{\text {symb }}\right)^{M-2}+ \\
& +2\left(\left(1-p_{0}^{*}\right)\left(1-\left(1-p_{0}^{*}\right)^{l_{r}-1}\right)\right) \times \\
& \times\left(1-p_{\text {symb }}\right)^{M-3}+ \\
& +(M-4) p_{\text {symb }}\left(1-p_{\text {symb }}\right)^{M-3} .
\end{aligned}
$$

Тоді ймовірність встановлення правильного циклового синхронізму за $l$ прийнятими фрагментами

$$
P_{\text {true }}=P_{1} P_{2-4} \text {. }
$$

Підставляючи вирази (3) i (4) для $P_{1}$ і $P_{2-4}$ до (5), отримаємо

$$
\begin{aligned}
& P_{\text {true }}=\left(1-p_{\text {symb }}\right)^{M-1} \times \\
& \times\left(\begin{array}{l}
1+2\left(\left(1-p_{0}^{*}\right)\left(1-\left(1-p_{0}^{*}\right)^{l_{r}-1}\right)\right)+ \\
+(M-5) p_{\text {symb }}
\end{array}\right) .
\end{aligned}
$$

Імовірність встановлення хибного циклового синхронізму за $l$ прийнятими фрагментами визначається ймовірністю виникнення події, за якої уточнена послідовність $R$ буде циклічно зсунутою синхрокомбінацією 3 точністю до символу суфікса за умови, що перший і останній його біти змінені не будуть. Таким чином, ця ймовірність залежить від розподілу відстаней Хеммінга від синхрокомбінації до їі циклічних зсувів. Такий розподіл для перестановок, наведених у таблиці 2, представлений у таблиці 3.

Таблиця 3 - Розподіл відстаней Хеммінга від синхрокомбінації до ії циклічних зсувів

\begin{tabular}{|c|c|c|c|c|c|c|c|}
\hline $\begin{array}{c}\text { № переста- } \\
\text { новки в таб- } \\
\text { лиці 2 }\end{array}$ & 6 & 8 & 10 & 12 & 14 & 16 & 18 \\
\hline 1 & 0 & 1 & 4 & 12 & 0 & 6 & 0 \\
\hline 2 & 2 & 2 & 2 & 7 & 2 & 8 & 0 \\
\hline 3,5 & 0 & 2 & 4 & 6 & 8 & 3 & 0 \\
\hline 4,7 & 2 & 0 & 4 & 11 & 0 & 2 & 4 \\
\hline 6,9 & 2 & 2 & 2 & 5 & 6 & 6 & 0 \\
\hline 8,10 & 0 & 2 & 4 & 7 & 6 & 4 & 0 \\
\hline 11 & 0 & 4 & 2 & 7 & 4 & 6 & 0 \\
\hline 12 & 2 & 2 & 2 & 6 & 4 & 7 & 0 \\
\hline
\end{tabular}

Імовірність того, що уточнена послідовність $R$ буде циклічно зсунутою синхрокомбінацією, дорівнює

$$
P_{\text {shift }}=\sum_{t=1}^{n} f(t)\left(p_{0}^{*}\right)^{t}\left(1-p_{0}^{*}\right)^{n-t},
$$

де $f(t)$ - кількість помилок кратності $t$ в уточненій послідовності $R$, які призводять до циклічного зсуву синхрокомбінації. Розподіл значень $f(t)$ якраз і наведено в таблиці 3. Значення $f(t) \equiv 0$ для всіх $t$, відсутніх у цій таблиці.

Розроблений метод передбачає можливість неправильного розпізнавання одного символу суфікса синхрокомбінації. Тому кратність помилки в уточненій послідовності $R$, яка призводить до циклічного зсуву синхрокомбінації, може відрізнятися на відстань Хеммінга від оригінального символу синхрокомбінації до пошкодженого символу уточненої послідовності $R$. Оскільки вага кожного

(C) Е. В. Фауре, В. В. Швидкий, А. І. Щерба, О. О. Харін, Б. А. Ступка, 2020 DOI: $10.24025 / 2306-4412.4 .2020 .222439$ 
символу помилки, яка переводить синхрокомбінацію до їі циклічного зсуву, невідома, їі ймовірність можна оцінити зверху виразом $\left(1-p_{0}^{*}\right)^{l_{r}}$. Кількість можливих помилок ваги $t$ збільшується в кількість разів, що відповідає кількості всіх варіантів бітових помилок для кожного $з$ символів суфікса - добутку суми комбінацій помилок символу на кількість символів суфікса. Таким чином, імовірність встановлення хибного циклового синхронізму за $l$ прийнятими фрагментами можна оцінити зверху наступним чином:

$$
P_{\text {false }} \leq \sum_{t=1}^{n} f(t)\left(\begin{array}{l}
(M-4) \sum_{j=0}^{l_{r}} C_{l_{r}}^{j} \times \\
\times\left(p_{0}^{*}\right)^{\left|t-l_{r}\right|}\left(1-p_{0}^{*}\right)^{n-\left|t-l_{r}\right|}+ \\
+2 \sum_{j=0}^{l_{r}-1} C_{l_{r}-1}^{j} \times \\
\times\left(p_{0}^{*}\right)^{\left|t-l_{r}+1\right|}\left(1-p_{0}^{*}\right)^{n-\left|t-l_{r}+1\right|}
\end{array}\right)
$$

Результати досліджень. Для перевірки ефективності роботи розробленого методу встановлення циклового синхронізму побудовано програмну модель передавання даних. Алгоритм роботи системи циклової синхронізації моделі зображено на рисунку 3.

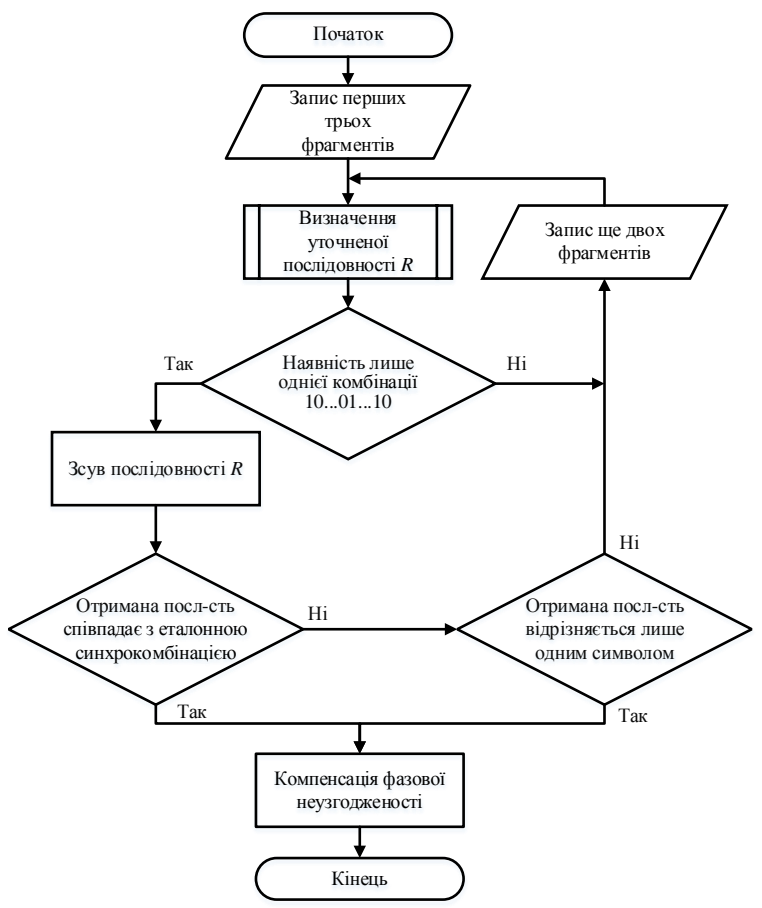

Рисунок 3 - Алгоритм роботи системи циклової синхронізації
Як синхрокомбінацію використано перестановку 3 з таблиці 2 .

Графік експериментально визначеної на 10000 випробуваннях залежності відносної частоти встановлення циклового синхронізму від фіксованого значення коефіцієнта накопичення $l$ для ймовірності бітової помилки $p_{0} \in\{0.1,0.2,0.3,0.4\}$ зображено на рисунку 4.

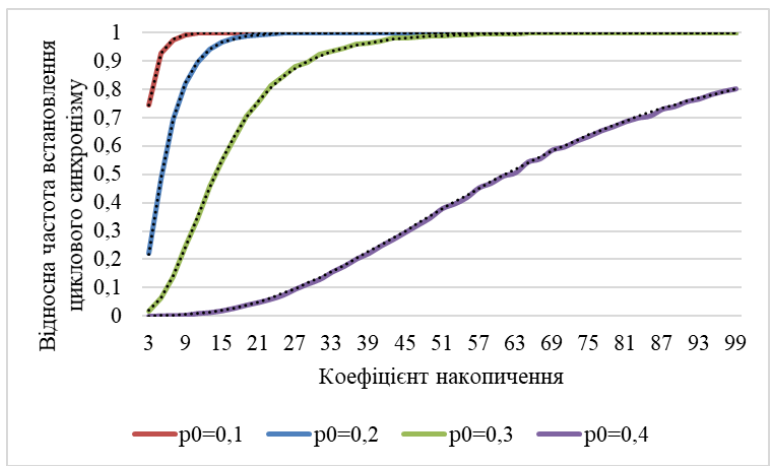

Рисунок 4 - Графік залежності відносної частоти встановлення циклового синхронізму від фіксованого значення коефіціснта накопичення

На рисунку 4 пунктиром показано також відповідні графіки теоретичних залежностей $P_{\text {true }}$ від $l$ відповідно до виразу (6).

Графік експериментально визначеної на 10000 випробуваннях залежності відносної частоти встановлення циклового синхронізму від коефіцієнта накопичення $l$ для розробленого алгоритму й імовірності бітової помилки $p_{0} \in\{0.1,0.2,0.3,0.4\}$ зображено на рисунку 5.

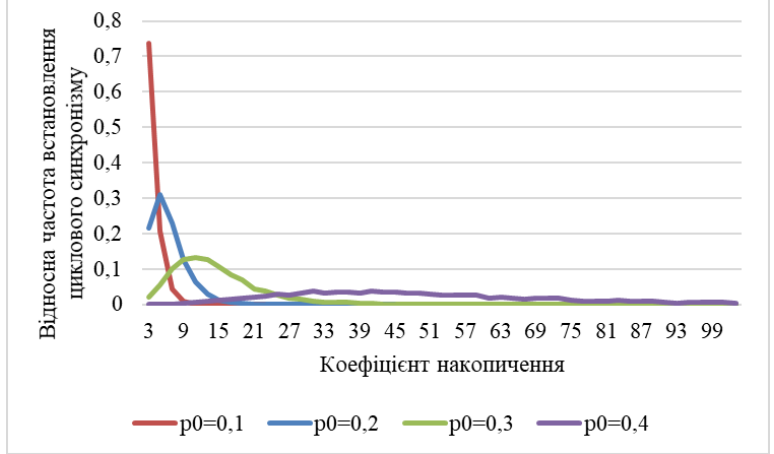

Рисунок 5 - Графік залежності відносної частоти встановлення циклового синхронізму від коефіціснта накопичення

На рисунку 6 зображено графік експериментально визначеної інтегральної функції часу входження в синхронізм (імовірності

(C) Е. В. Фауре, В. В. Швидкий, А. І. Щерба, О. О. Харін, Б. А. Ступка, 2020 DOI: $10.24025 / 2306-4412.4 .2020 .222439$ 
встановлення циклового синхронізму за $l$ прийнятими фрагментами), побудованої на основі зображеної на рисунку 5 залежності відносної частоти встановлення циклового синхронізму від коефіцієнта накопичення $l$.

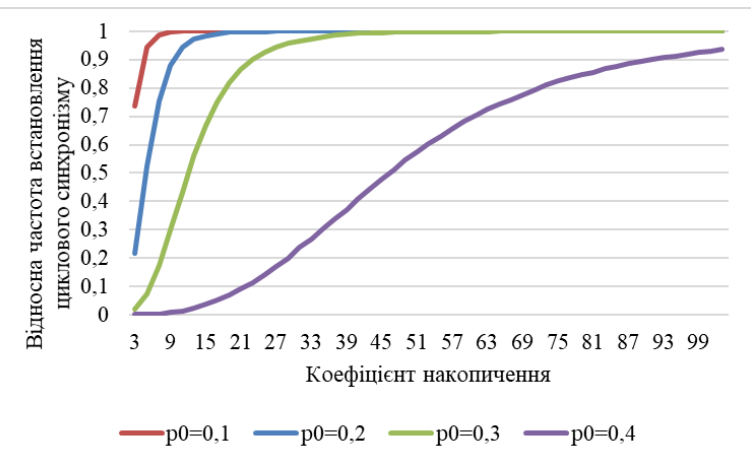

Рисунок 6 - Графік залежності ймовірності встановлення циклового синхронізму від коефіціснта накопичення

Графіки залежностей оцінок зверху ймовірності встановлення хибного циклового синхронізму від кількості прийнятих фрагментів для синхрокомбінації 13 таблиці 2 для ймовірності бітової помилки $p_{0} \in\{0.1,0.2,0.3,0.4\}$ зображено на рисунку 7 .

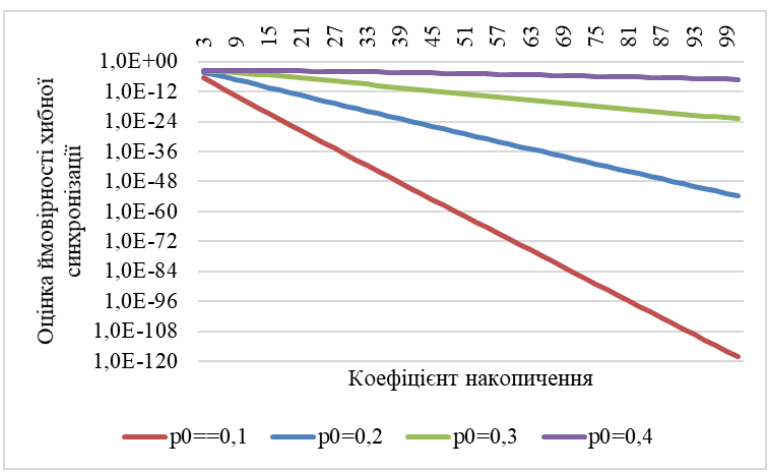

Рисунок 7 - Графіки залежностей оцінок зверху ймовірності встановлення хибного циклового синхронізму від коефіціснта накопичення

Під час експериментального дослідження розробленого методу для перестановки 3 3 таблиці 2 та значень імовірності бітової помилки $p_{0} \in\{0.1,0.2,0.3,0.4\}$ випадків встановлення хибного циклового синхронізму не виявлено для 10000 випробувань.

Зауважимо, що за показником імовірності встановлення хибного циклового синхронізму, зважаючи на показники 3 таблиці 3, найбільш ефективним є використання перестанов- ки 13 таблиці 2. Як підтвердження на рисунку 8 зобразимо графіки залежностей оцінок зверху ймовірності встановлення хибного циклового синхронізму від кількості прийнятих фрагментів для синхрокомбінацій 1, 2, 3, 113 таблиці 2 для ймовірності бітової помилки $p_{0}=0.4$.

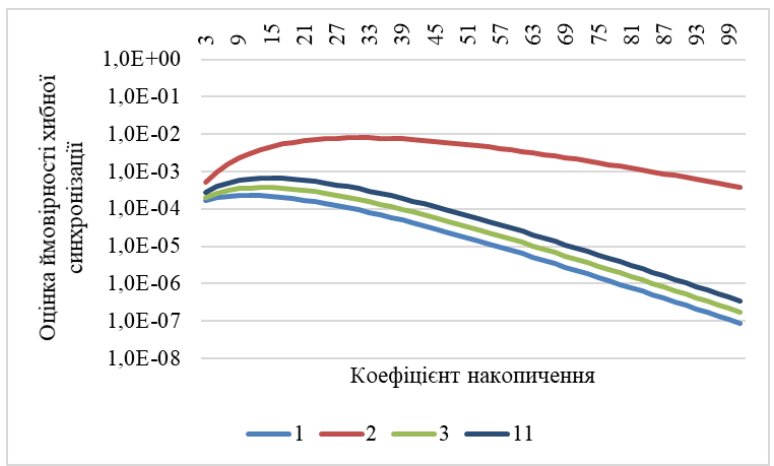

Рисунок 8 - Графіки залежностей оцінок зверху ймовірності встановлення
хибного циклового синхронізму
від коефіціснта накопичення
для ймовірності помилки $p_{0}=0.4$

Обговорення результатів. У першу чергу, зауважимо, що зображені на рисунку 4 теоретичні й експериментальні залежності узгоджуються між собою за критерієм Пірсона 3 близькими до одиниці досягнутими рівнями значущості (p-value), інтерпретованими згідно з викладеною в [17] методологією. Це свідчить про коректність побудови програмної моделі.

Пояснимо відмінності залежностей, продемонстрованих на рисунках 4 і 6 . На рисунку 4 показано відносну частоту встановлення циклового синхронізму за умови, якщо значення коефіцієнта накопичення є фіксованим і не змінюється в процесі роботи системи циклової синхронізації. Рисунок 5 демонструє відносну частоту встановлення циклового синхронізму за умови, що коефіцієнт накопичення поступово збільшує своє значення залежно від результату пошуку на попередньому етапі. Як можна бачити 3 графіків 4 і 6 , ці відносні частоти не є однаковими, а значення $P_{\text {true }}$, обчислене за (6) для заданих коефіцієнта накопичення встановлення циклового синхронізму $l_{d e f}$ i ймовірності бітової помилки $p_{0}$, менше за суму зображених на рисунку 5 відносних частот встановлення циклового синх- 
ронізму для $l \leq l_{d e f}$. Ця ситуація обумовлена тим, що множина подій, за яких відбувається циклова синхронізація за фіксованого значення коефіцієнта накопичення $l_{d e f}$, не складається 3 множин подій, за яких відбувається циклова синхронізація під час поступового збільшення коефіцієнта накопичення $l \leq l_{d e f}$. Так, наприклад, пошкодження біта в уточненій послідовності $R$, обчисленій за $l$ фрагментами, за умови, що в обчисленій за $(l-2)$ фрагментами уточненій послідовності бітові помилки відсутні, породжує ситуацію, коли таку подію враховано у відносній частоті встановлення циклового синхронізму для коефіцієнта накопичення $(l-2)$, проте не враховано для коефіцієнта накопичення $l$.

Висновки. У роботі розроблено метод циклової синхронізації для систем зв'язку з нероздільним факторіальним кодуванням, який за рахунок використання як синхрокомбінації перестановки заданої довжини, ії поділу на префіксну та суфіксну частини, а також мажоритарної обробки прийнятих фрагментів дає можливість досягти циклової синхронізації в умовах впливу в каналі зв'язку завад високої інтенсивності. Метод може бути використаний для зменшення часу входження в синхронізм і підвищення стійкості телекомунікаційної системи в умовах впливу завад.

Розроблено та реалізовано алгоритм, що реалізує запропонований метод.

Технічним результатом, на який спрямовано застосування запропонованого методу в телекомунікаційній системі, $€$ зменшення втрати часу сеансу зв' язку на виконання функції встановлення з'єднання i, отже, збільшення часу в сеансі на передавання даних користувача $\mathrm{i}$, як наслідок, на збільшення пропускної здатності каналу зв'язку.

Разом 3 тим, розроблений метод може бути ефективним для реалізації не тільки в системах з нероздільним факторіальним кодуванням. Це питання є предметом подальших досліджень.

Подяка. Роботу виконано в рамках науково-технічної (експериментальної) розробки молодих вчених «Розробка мобільної системи захищеного інформаційного обміну для військових i цивільних підрозділів державних структур» (№ ДР 0120U102607).

\section{Список використаних джерел}

[1] D. Hercog, Communication Protocols. Principles, Methods and Specifications. Springer International Publishing, 2020.

[2] H. König, Protocol Engineering. SpringerVerlag Berlin Heidelberg, 2012.

[3] M. Popovic, Communication Protocol Engineering. 2nd ed., CRC Press, 2018.

[4] Э. В. Фауре, "Факториальное кодирование с восстановлением данных", Вісник Черкаського державного технологічного університету, № 2, с. 33-39, 2016.

[5] Е. В. Фауре, О. О. Харін, В. В. Швидкий, та А. I. Щерба, "Спосіб факторіального кодування з відновленням даних", Укр. nam. 117004, Черв. 12, 2017.

[6] Э. В. Фауре, "Факториальное кодирование с исправлением ошибок", Радіоелектроніка, інформатика, управління, № 3 , c. 130-138, 2017.

[7] Е. В. Фауре, О. О. Харін, В. В. Швидкий, та А. І. Щерба, "Спосіб факторіального кодування з виявленням і виправленням помилок", Укр. nam. 121361, Груд. 11, 2017.

[8] E. V. Faure, A. I. Shcherba, and A. A. Kharin, "Factorial code with a given number of inversions", Radio Electronics, Computer Science, Control, vol. 2, pp. 143153, 2018.

[9] J. Massey, "Optimum frame synchronization", IEEE Transactions on Communications, vol. 20, no. 2, pp. 115119, April 1972.

DOI: 10.1109/ TCOM.1972.1091127

[10] R. Scholtz, "Frame synchronization techniques", IEEE Transactions on Communications, vol. 28, no. 8, pp. 1204-1213, August 1980.

DOI: 10.1109/TCOM.1980.1094813

[11] P. Kartaschoff, "Synchronization in digital communications networks", Proceedings of the IEEE, vol. 79, no. 7, pp. 1019-1028, July 1991.

DOI: $10.1109 / 5.84979$

[12] Hansheng Wang, Xiaoyi Qin, Lieguang Zeng, and Fuqin Xiong, "Coding, decoding, and recovery of clock synchronization in digital multiplexing system", IEEE Transactions on Communications, vol. 51, no. 5, pp. 825-831, May 2003.

DOI: 10.1109/ TCOMM.2003.811432 
[13] Б. Ф. Брегман, и В. В. Квашенников, "Способ кодовой цикловой синхронизации сообщений", РФ. пат. 2459366 , 2006.

[14] J. S. Al-Azzeh, B. Ayyoub, E. Faure, V. Shvydkyi, O. Kharin, and A. Lavdanskyi, "Telecommunication systems with multiple access based on data factorial coding", International Journal on Communications Antenna and Propagation (IRECAP), vol. 10, no. 2, pp. 102-113, 2020. DOI: $10.15866 /$ irecap.v10i2.17216

[15] S. Lin, and D. Costello, Error Control Coding. 2nd ed. Prentice Hall, 2004.

[16] J. J. Kong, and K. K. Parhi, "Interleaved convolutional code and its Viterbi decoder architecture", EURASIP J. Adv. Signal Process., 417892, 2003. DOI: 10.1155/ S1110865703309126

[17] A. Rukhin et al., "A statistical test suite for random and pseudorandom number generators for cryptographic applications", Spec. Pub. 800-22 rev. 1a, Gaithersburg, MD, NIST, 2010.

\section{References}

[1] D. Hercog, Communication Protocols. Principles, Methods and Specifications. Springer International Publishing, 2020.

[2] H. König, Protocol Engineering. SpringerVerlag Berlin Heidelberg, 2012.

[3] M. Popovic, Communication Protocol Engineering. 2nd ed., CRC Press, 2018.

[4] E. V. Faure, "Factorial coding with data recovery", Visnyk Cherkaskogo derzhavnogo tehnologichnogo universitetu, no. 2, pp. 3339, 2016. [in Russian].

[5] E. V. Faure, O. O. Kharin, V. V. Shvydkyi, and A. I. Shcherba, "Method of factorial coding with data recovery", Ukr. Patent 117004, June 12, 2017. [in Ukrainian].

[6] E. V. Faure, "Factorial coding with error correction", Radioelektronika, informatyka, upravlinnia, no. 3, pp. 130-138, 2017. [in Russian].

[7] E. V. Faure, O. O. Kharin, V. V. Shvydkyi, and A. I. Shcherba, "Method of factorial coding with error detection and correction", Ukr. Patent 121361, Dec. 11, 2017. [in Ukrainian].
[8] E. V. Faure,

A. I. Shcherba,

and A. A. Kharin, "Factorial code with a given number of inversions", Radio Electronics, Computer Science, Control, vol. 2, pp. 143$153,2018$.

[9] J. Massey, "Optimum frame synchronization", IEEE Transactions on Communications, vol. 20, no. 2, pp. 115119, April 1972, DOI: 10.1109/ TCOM.1972.1091127

[10] R. Scholtz, "Frame synchronization techniques", IEEE Transactions on Communications, vol. 28, no. 8, pp. 1204-1213, August 1980.

DOI: 10.1109/TCOM.1980.1094813

[11] P. Kartaschoff, "Synchronization in digital communications networks", Proceedings of the IEEE, vol. 79, no. 7, pp. 1019-1028, July 1991.

DOI: $10.1109 / 5.84979$

[12] Hansheng Wang, Xiaoyi Qin, Lieguang Zeng, and Fuqin Xiong, "Coding, decoding, and recovery of clock synchronization in digital multiplexing system", IEEE Transactions on Communications, vol. 51, no. 5, pp. 825-831, May 2003.

DOI: 10.1109/ TCOMM.2003.811432

[13] B. F. Bregman, and V. V. Kvashennikov, "Method of code frame synchronization of messages", RF. Patent 2459 366, 2006. [in Russian].

[14] J. S. Al-Azzeh, B. Ayyoub, E. Faure, V. Shvydkyi, O. Kharin, and A. Lavdanskyi, "Telecommunication systems with multiple access based on data factorial coding", International Journal on Communications Antenna and Propagation (IRECAP), vol. 10, no. 2, pp. 102-113, 2020. DOI: 10.15866/ irecap.v10i2.17216

[15] S. Lin, and D. Costello, Error Control Coding. 2nd ed. Prentice Hall, 2004.

[16] J. J. Kong, and K. K. Parhi, "Interleaved convolutional code and its Viterbi decoder architecture", EURASIP J. Adv. Signal Process., 417892, 2003. DOI: $10.1155 / \mathrm{S} 1110865703309126$

[17] A. Rukhin et al., "A statistical test suite for random and pseudorandom number generators for cryptographic applications", Spec. Pub. 800-22 rev. 1a, Gaithersburg, MD, NIST, 2010. 
E. V. Faure, Dr.Sc., professor,

e-mail: e.faure@chdtu.edu.ua

V. V. Shvydkyi, Ph.D., associate professor,

A. I. Shcherba, Ph.D., associate professor,

O. O. Kharin, Ph.D.,

B. A. Stupka

Cherkasy State Technological University

Shevchenko blvd, 460, Cherkasy, 18006, Ukraine

\section{METHOD OF CYCLIC SYNCHRONIZATION BASED ON PERMUTATIONS}

The method of cyclic synchronization of receiving and transmitting stations for telecommunication systems with inseparable factorial coding is developed and investigated. The method is aimed to work in conditions of strong interference in communication channel. The main idea for the proposed method of cyclic synchronization establishing is the following. A permutation is the synchrocombination. The synchrocombination construction is divided into a prefix part that defines the boundaries of synchrocombination symbols and a suffix part that defines the boundaries of the synchrocombinationpermutation. The increase in the reliability of synchrocombination transmission is provided by its multiple repeating and majority processing of the received fragments.

Probabilistic indicators of the developed method - the probability of correct synchronism establishing and the probability of incorrect synchronism establishing are theoretically determined and investigated. The block diagram of the cyclic synchronizing device is developed. The software model of data transmission, which implements the developed algorithm for establishing cyclic synchronism, is built. The experimentally obtained probabilistic characteristics of the developed method are estimated. Their compliance with theoretical indicators has been confirmed.

The technical result the proposed method is aimed at is to reduce the loss of communication session time to perform the function of establishing a connection and, therefore, to increase the session time for transmission of user data and, consequently, for increase of channel bandwidth communication.

The developed method can be effective for implementing not only in systems with inseparable factorial coding but also in classical data transmission systems where a standard delimiter is used.

Keywords: factorial coding, synchrocombination, probability of synchronism establishing, accumulation coefficient, high intensity interference.

Стаття надійшла 25.11.2020

Прийнято 18.12.2020

(C) Е. В. Фауре, В. В. Швидкий, А. І. Щерба, О. О. Харін, Б. А. Ступка, 2020 DOI: $10.24025 / 2306-4412.4 .2020 .222439$ 